\title{
Effect of Solid Fuel Particle Size on Burning Rate Using Computational Analysis
}

\author{
Thomas Marino', Vahid Motevalli² \\ ${ }^{1}$ NSWC \\ West Bethesda, MD, USA \\ ${ }^{2}$ Tennessee Technological University, College of Engineering \\ 1010 N. Peachtree Ave., Clement Hall, Cookeville, TN USA \\ thomas.marino@navy.mil; vmotevalli@tntech.edu
}

\begin{abstract}
Aluminium as fuel using steam oxidant is an attractive energy source in combustion systems where high energy densities are desired. Most experimental and computational work has been done for combustion chamber operating at or near atmospheric pressures using oxidants of air or pure oxygen. Experimental studies conducted for particles ranging in size of 10-700 microns suggest that smaller particles may experience shorter combustion residence time. This computational analysis provides a detailed examination of metal-fuel combustion at pressures above atmospheric and shows that combustion performance of aluminium particles directly relate to the particle size and distribution. The computational model is applied to a linear-type dump combustor. The effects of a range of particle sizes are investigated using monodispersed and polydispersed particle distributions. Characterization of the combustion process is addressed by studying particle ignition delay, burn time, and particle emission as a function of particle diameter and mass fraction. The computational models include non-isotropic turbulence, empirically derived ignition and reaction rate criteria as well as convective and radiant heat transfer. The commercial computational fluid dynamics solver Fluent is used to perform these computations. Sub-models are added to the standard Fluent capability for reaction rate equations, oxide nucleation in the discrete and continuous phases, dissociation, particle emissivity, and particle drag. The numerical results indicate that polydispersed fuel can lead to better overall performance than monodispersed fuel with the same mean diameter at 20 microns and below. Ignition and burn times can become accelerated in distributions relative to the monodispersed sizes for the same mean diameters for the full range of sizes investigated. The optimum ignition time was determined to be at the 10 -micron polydispersed distribution. Burn time can be optimized with a distribution mean of 10 microns, with diminishing increase and variability above a mean distribution of 20 microns, as well as very little increase in maximum burn time.
\end{abstract}

Keywords: Metal combustion, particle size, numerical analysis, polydispersed

\section{Introduction}

Combustion using aluminium particles as fuel is an attractive energy source where high energy densities are desired. The Office of Naval Research (ONR) has been investigating the potential of an engine that burns aluminium with oxygen from seawater [1]. A sea-breathing propulsion system does not need to carry its oxidizer with it, saving vehicle space and weight, and allowing it to more easily maintain the speeds and range needed to be an efficient platform. This seawaterbreathing engine can be used in a high-speed torpedo and small, unmanned submarines. Applications can be extended for an engine that can breathe oxygen from air or CO2. Ideally the same engine could be developed to operate across platforms and operating environments, including terrestrial air breathing combat vehicles like the M1 Abrams Tank, subsonic stealth aircraft, and Mach 6 to 15 intercept missiles. An advanced technology demonstration (ONR Advanced Technology Demonstration 1999) proposed replacing the battery and diesel configuration on submarines. This technology is also being presented as a replacement for batteries, fuel cells, and Sterling Engines on small submarines and unmanned undersea vehicles [2 and 3]. An aluminium combustor could also be used to power a steam generator, which could be used in fuel cells for mining methane from a hydrate lattice and for cracking of the methane molecule. High-pressure combustion chambers are also desired to drive small turbines that can be used for power sources. Still in the conceptual stages are projects that would use aluminium-fuelled propulsion for a combination tank and submarine, as well as a combination airplane and submarine. 
Most of the literature available presents experimental results of single particle ignition and combustion, at low pressures around atmospheric, with air or oxygen as oxidizing species. Most rocket motors operate at pressures in the 70 atmospheres range, and operate in the absence of air or oxygen. Metal-fuelled combustors for power sources typically operate in the 15 atmospheres range and may use air, oxygen, $\mathrm{H} 2 \mathrm{O}$, or $\mathrm{CO} 2$ as oxidizing species.

Aluminium has some unique properties that have complicated efforts to understand how its combustion process works. Aluminium does not decompose to a vapour at the burning surface. The typical temperature of propellant burning surfaces is about $873 \mathrm{~K}, 60 \mathrm{~K}$ below the $933 \mathrm{~K}$ melting point of aluminium. The melting point of aluminium corresponds closely to temperatures normally present on propellant burning surfaces [4].

The particle surfaces are coated with an impervious refractory coating of Al2O3. The oxide, with a melting point of $2345 \mathrm{~K}$, constitutes about $0.5 \%$ of the particle mass (for particle in the range of about 25 micron particles). Once the $\mathrm{Al} 2 \mathrm{O} 3$ oxide coating is broken down, $\mathrm{Al}$ is extremely reactive in the combustion zone, but its reaction rate is limited by its low vapour pressure (high boiling point). Appreciable vapour pressures are not experienced until heated close to its boiling point of $2750 \mathrm{~K}$ [4].

Under most conditions the preceding characteristics cause the aluminium in propellant flames to burn primarily as droplets in the hot gas phase region and beyond the usual combustion zone, although some oxidation can occur during the residence time on the burning surface. At high temperatures, the droplets contain both aluminium and molten Al2O3, which tend to separate into lobes of the droplets because $\mathrm{Al}$ and $\mathrm{Al} 2 \mathrm{O} 3$ are insoluble.

\section{Previous Experimental Research}

Unlike their terrestrial air/hydrocarbon counterparts that produce gaseous products $(\mathrm{CO} 2$ and $\mathrm{H} 2 \mathrm{O})$, sea-breathing, metal-fueled combustors for underwater applications produce condensed phase combustion products. These metal oxides can be in the liquid or solid phase, depending upon the local combustor temperature and the melting temperature of the specific species. In the case of aluminium/water combustion, the adiabatic flame temperature of a stoichiometric mixture is well above the freezing temperature $(2300 \mathrm{~K})$ of aluminium oxide, so it forms as a liquid. The liquid aluminium oxide products can impact and freeze on the cool combustor walls, forming slag. In the recent Defense Advanced Research Projects Agency (DARPA) Loki vortex combustor testing, this slag accumulated near the aluminium and steam injectors and adversely affected operation. In this case, slag deposit in this vortex combustor formed within 30 seconds and caused early shutdown of the test. Liquid aluminium oxide particles can also agglomerate or coalesce into larger droplets. Besides having a propensity to settle out of the gas stream, these larger droplets can freeze into larger "clinkers" which can then complicate separation of the solids from the gas. Adequate separation and overboard disposal of solid products is essential for achieving a long-duration Rankine cycle power plant. This is less of an issue for the short-duration direct thruster application required of a High Speed Supercavitating Vehicle (HSSV); nevertheless, slag accumulation on the combustor walls must be controlled to ensure the most efficient and reliable thrust or gas generation operation possible.

Foote, et al. [5] studied aluminium/steam and aluminium/oxygen combustion in a linear chamber. Tests were run for ten minutes, and optical temperature data were taken at several different axial locations. Slagging was observed when burning aluminium with both air and steam. About 25 percent of the solid products remained inside the combustor with steam as the oxidizer. The data were only taken at 1 atmosphere. The relevancy of these tests and other test results examined is limited, due to the pre-burning of the aluminium in an oxidizer grain and the injection of the water/hydrogen peroxide mixture as a liquid. A compilation of various laboratory studies of aluminium combustion, including aluminium with water/steam, were made by Miller [6] and Beckstead [7]. The majority of these data were for single particles or particles in oxidizer atmospheres other than steam. In the small-scale experimental configurations of these tests, slagging was not an issue and therefore was not addressed. Furthermore, in most of these tests, particle-particle and overall 2-phase flow phenomena were studied in only the most peripheral manner.

\section{Approach}

The focus of the research results included here is on advancing the understanding of solid fuel particle size effect on combustion properties. The approach is outline below:

1. Employ a steady state Navier-Stokes solver, using an Eulerian reference frame to model the continuous gas phase, and a Lagrangian reference frame to model the particles in a discrete phase, and to simulate the combustion physics of aluminium fuel steam oxidizer in a two dimensional axisymmetric linear dump-type chamber using monodispersed and polydispersed fuel sizes. 
2. Examine coupled physical submodels, developed as part of this investigation, for oxide formation, ignition prediction, combustion rates of reaction, and oxide dissociation with the Navier Stokes equations, as well as radiative coupling.

3. Compute the flow field, temperatures, species concentrations, radiative emission, and radiance to perform a comparative study on the numerical burn times, ignite times, combustion efficiency with published results.

4. Examine the flow dynamics and thermal field of each result with different initial fuel sizes to acquire a comprehensive understanding of its influence on burn times, ignite times, combustion efficiency.

5. Identify the role that the initial fuel size has on the combustion properties such as temperatures, radiative emission, and radiance.

6. Understand how the combustor performance varies with initial fuel sizes, injected as monodispersed, in a range of 5 microns to 40 microns, and as polydispersed with a mean size ranging from 10 microns to 30 microns.

7. Examine the influence and significance of radiative coupling, measured as radiative intensity and radiative emission.

The results presented in this paper are limited to the ignition of particles and the effect of particle size. Ignition studies [8 and 9] suggest that the ignition environment is augmented by increases in pressure, temperature, and available spark energy, while impeded by increased velocities and turbulent intensity. The studies also suggest that the amount of energy required to initiate ignition are significantly influenced by stoichiometric fuel/air/ratios. The heat released by the desired combustion process must be greater than the amount of heat lost to the surroundings by radiant heat transfer or by turbulent diffusion in order for combustion to be self-sustaining. Ignition should be attempted at fuel air ratios very close to stoichiometric if heating the excess air or fuel is not desired. However, for example, $\mathrm{H}_{2}-\mathrm{O}_{2}$ fueled rockets prefer excess $\mathrm{H}_{2}$ to maximize specific impulse.

Ignition can follow two potential pathways [10 and 11]. The first is the destruction of a solid oxide layer surrounding the metal fuel and exposing it to the oxidizing atmosphere. The second pathway is described as self-heating of the particle due to oxidizer diffusion through the oxide coat. These pathways are depicted in Figure 1. Much of the research on metal particle fuel combustion indicates that the first pathway is the dominant mechanism, with ignition temperatures in the range of 1700-2200 $\mathrm{K}$ for the particle sizes in the general range under consideration (i.e. 10-50 micron). This mechanism is similar to liquid fuel droplet combustion where the reaction is limited by diffusion of oxidizer toward the particle and vaporized metal away from the particle surface.

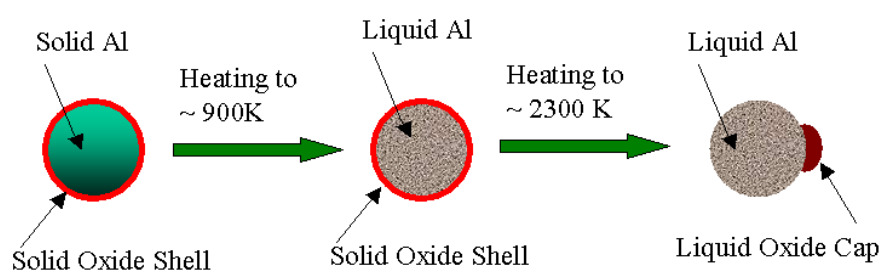

Fig. 1: Heating process of a typical, spherical aluminium particle, from inert heating, to surface reaction threshold, to diffusion reaction threshold.

An empirically derived ignition temperature [6] will be used to predict which pathway is occurring on the particle at a given time. This empirically derived threshold is based on experimentation of single particles of aluminium with steam oxidation [5, 12, 13 and 14]. This temperature is only used in the computational model to determine which reaction mechanism is active. A general rule of thumb is to use the aluminium oxide melting temperature as the criterion for whether any reaction occurs. Below this temperature, no self-heating or diffusion dominated rate of reaction is permitted.

\section{Model Validation}

The computational models were compared to the published experimental results performed by Foote et al. [15] and the published computational results of Miller [6]. Miller's computational results are validated to Foote's experimental results. The computational model took into account the physics described in Figure 2.

Foote uses a dump type combustor comprised of a 6-inch long injector and a 48-inch long main chamber. The inside diameter of the combustor is 4 inches. The Foote experiments were performed using aluminium fuel particles with a mean diameter size of $17 \mu \mathrm{m}$ at a flow rate of $0.005 \mathrm{~kg} / \mathrm{sec}$ using steam as the oxidizer species. Most of the oxidizer species is 
used as fuel particle ejector motive gas. The remaining $10 \%$ of the required oxidizer is added in the ejector tailpipe. The stoichiometric fuel-oxidizer ratio by mass is about 1.10 based on the combustion reaction. Steam for the oxidizer is supplied at $600 \mathrm{~K}$ at $10 \mathrm{ATM}$, or 1.034E6 Pa. Foote estimated injection velocities of steam oxidizer and aluminium fuel to be $30.48 \mathrm{~m} / \mathrm{sec}$.

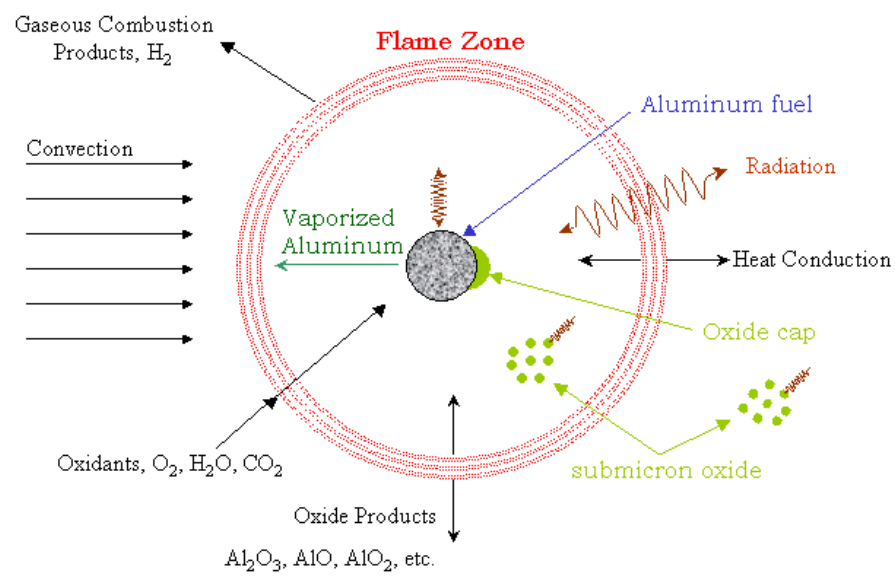

Fig. 2: Aluminum combustion process, showing heat transfer mechanisms, participating species, phases, and flame zone.

Foote's primary interests were in determining ignition requirements, combustor heat transfer, and residence time requirements. Measurements of combustion temperature are made at discrete locations using a thermocouple. Radiation intensity in the mostly visible wavelength interval of $400 \mathrm{~nm}$ to $800 \mathrm{~nm}$ is determined by making spectrometer measurements at several locations. Bulk temperatures are inferred by fitting a Wein's Law curve [16] to the measured radiance. Combustion products are collected at several axial locations and subjected to eudiometric analysis [17] to determine particle size distribution and composition. The results of the eudiometric analysis are then used to estimate the combustion efficiency. Table 1 shows a comparison of the bulk properties for the computational results and the Foote measured results.

Table 1 - Comparison of validation case computational results and Foote's experimentally determined results.

\begin{tabular}{|c|c|c|c|}
\hline Parameter & Foote & Computation & \% difference \\
\hline Flame Temperature & $2575 \mathrm{~K}$ & $2557 \mathrm{~K}$ & $0.7 \%$ \\
\hline Ignition Distance & $457 \mathrm{~mm}$ & $419 \mathrm{~mm}$ & $8.3 \%$ \\
\hline Mean Velocity & $27 \mathrm{~m} / \mathrm{sec}$ & $26 \mathrm{~m} / \mathrm{sec}$ & $3.7 \%$ \\
\hline Residence Time & $44 \mathrm{~ms}$ & $45 \mathrm{~ms}$ & $2.3 \%$ \\
\hline Radiance & $133 \mathrm{~kW} / \mathrm{m}^{2}$-micron & $135 \mathrm{~kW} / \mathrm{m}^{2}$-micron & $1.5 \%$ \\
\hline
\end{tabular}

Foote estimated combustion efficiency by taking samples of particle laden combustion gas through probes inserted at various locations from the downstream end of the combustor. These samples are then analyzed for unburned aluminium using the eudiometric analysis. The computational combustion efficiency is determined by sampling particle trajectory data at discrete points along the combustor and determining the mass fraction of fuel and condensed oxide, subtracting the 


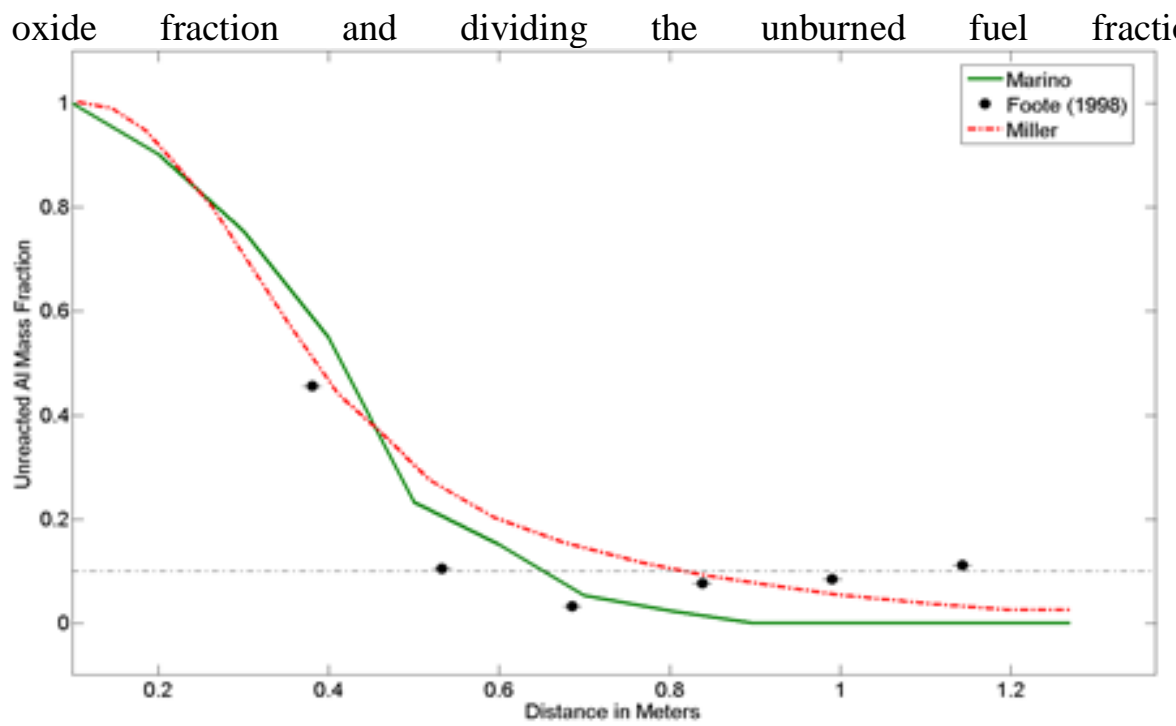

by the initial particle mass.

Fig. 3 shows the comparison of combustion efficiency, represented as mass fraction of unreacted aluminium fuel, between the Foote experimental data, the Miller computational results, and the computational results from Marino [19] which used an Eulerian-Lagrangian formulation.

Fig. 4 shows the comparison of the temperature estimate provided by Foote, the computed temperature provided by Miller, and the computational results investigated as part of this work. The discrete ordinate method provides the best prediction of temperature at all points, particularly in the primary ignition zone (diffusion-limited) and in the area of full steady combustion (ignition to extinction of reactant), and with the exception of the Foote measurement at about 0.55 meters along the main chamber. Radiative cooling accounts for the drop in flame temperature from the adiabatic flame temperature of $3050 \mathrm{~K}$ to computationally determined $2557 \mathrm{~K}$. The adiabatic flame temperature (AFT) and computed flame temperature are above the melting point of the oxide, so it is expected to form as sub-micron soot. Two radiation modelling methods were examined as part of this validation study; the discrete ordinate model and the two-flux P1 model. Both radiation models performed well, but the discrete ordinate model performed better in the initial combustion zone, about 0.2 to 0.3 meters downstream of the point of injection.

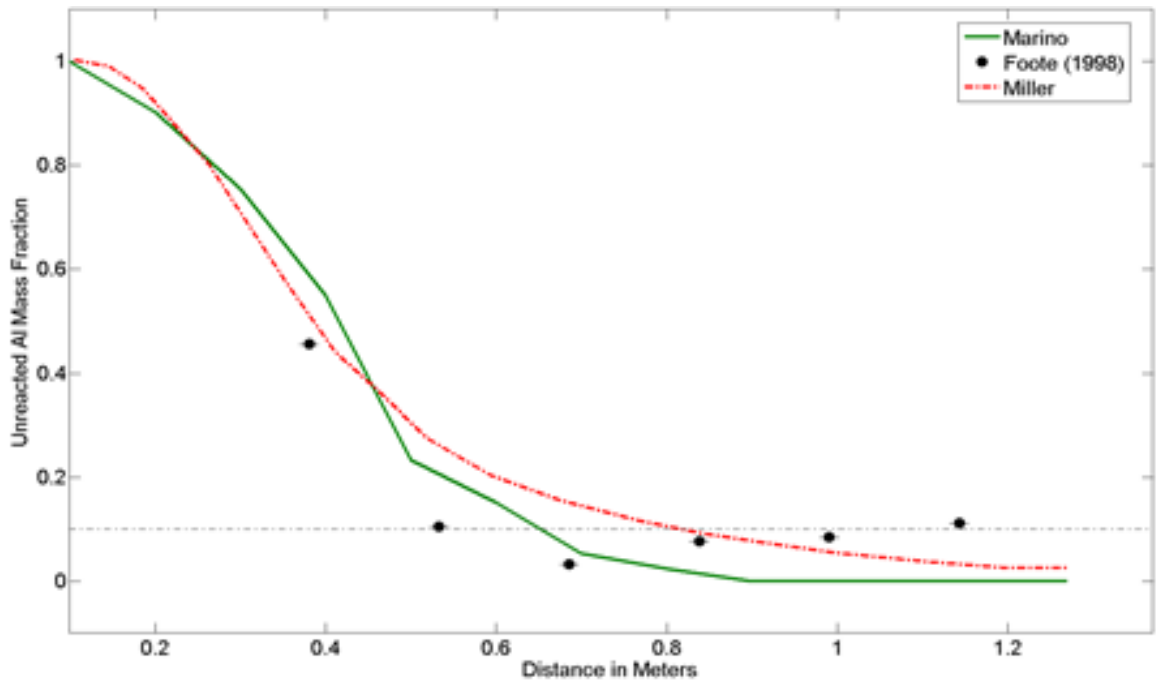

Fig. 3: Combustion efficiency comparisons of validation case computational results using an Eulerian-Lagrangian reference frame, Foote et al.'s [15] experimentally determined results, Miller's [6], and the two-dimensional axisymmetric computational results using an Eulerian-Eulerian formulation by Marino [19]. 


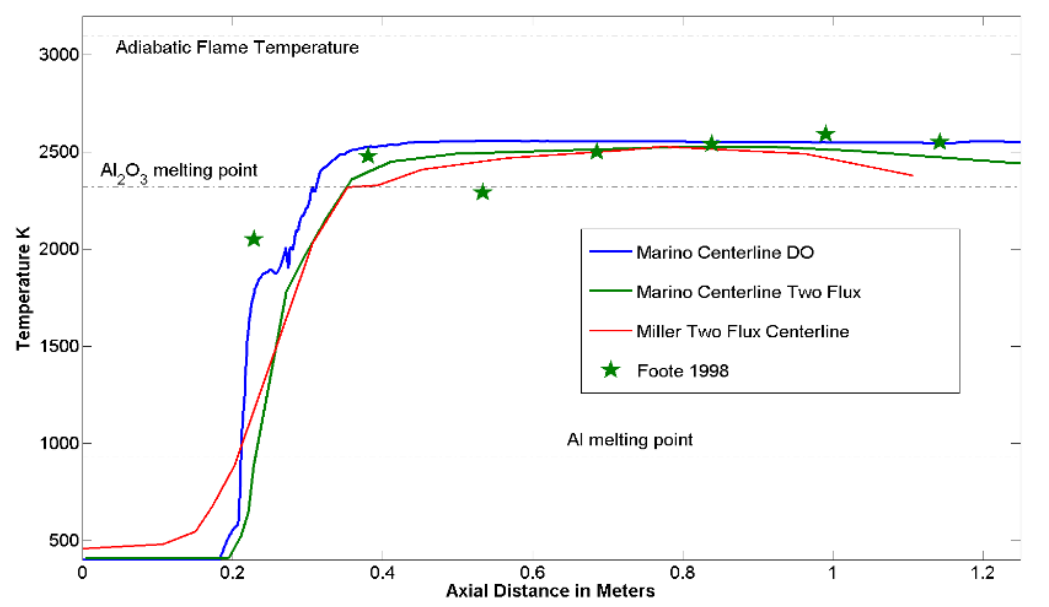

Fig. 4: Temperature comparisons of validation case computational results using the two-flux and discrete ordinate radiation models, Foote et al.'s [15] experimentally determined results, and Miller's [16], and the computational results using a two-flux radiation model of Marino [19].

\section{Results and Discussion}

In order to examine the effect of particle size on the combustion process, computational investigation of the described process is performed using monodispersed and polydispersed aluminium particles. Particle sizes for monodispersed studies range from 5 microns to 40 microns, at 5-micron increments. The particle size is constant as measured from the point of injection within the domain representing the combustor assembly. The mass flow rate remains the same for all monodispersed cases; therefore, the number of particles increases as the particle size decreases. The discrete ordinate radiation model is executed for this group of computations.

A sample comparison of the reaction front can first be represented using product and reactant species source contours for all polydispersed cases shown in Figure 5, and monodispersed cases shown in Figure 6. These mass source contours display the contributions these species make when transitioning to and from the discrete phase or continuous phase. These figures show the mass fraction of aluminium oxide and the particles in the discrete phase, indicating where the particles are inert or reacting, as a function of position, and provide the insight to determine the nature of the reaction front. A positive source indicates the species is added to the continuous phase. These would include the aluminium oxide product species, as well as the hydrogen product species. This would include the oxidant species, $\mathrm{H}_{2} \mathrm{O}$. The release of product source terms and consumption of oxidant species indicate the spatial point of ignition to the spatial point of fuel burnout or extinction. The mass fraction contours of Figure 5 and Figure 6 indicate the discrete location of species, which are influenced by mass source terms, continuous phase convection, or other forces. 


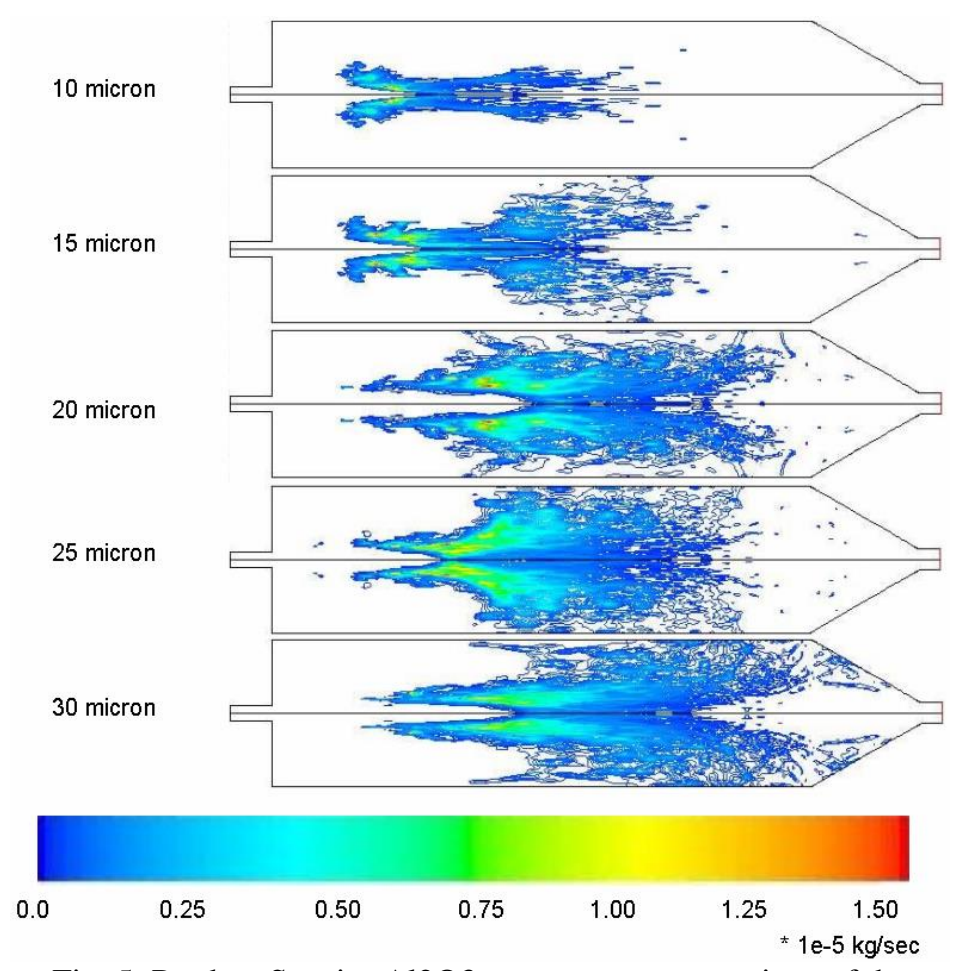

Fig. 5: Product Species Al2O3 source term comparison of the polydispersed cases with radiation modeled

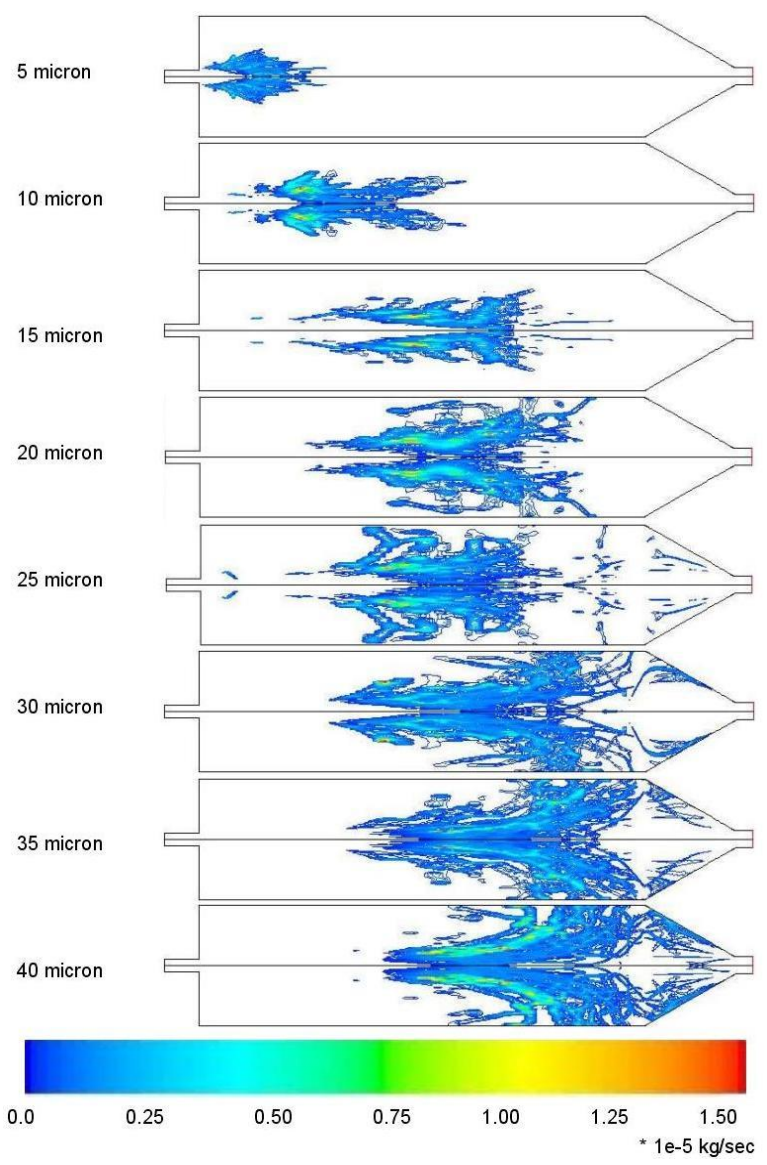

Fig. 6: Product Species Al2O3 source term comparison of the monodispersed cases with radiation modelled

For the 5-micron case the reaction front size is comparatively small in length and width due to the very rapid vaporized fuel mass flow rate. These figures suggest that the continuous phase for smaller particles has a short, narrow combustion front, while the larger particles stretch the reaction into a larger volume of the combustor. The release of product mass source terms in a smaller volume yields an increase in the surrounding thermal thickness but also an increase in optical length due to a denser radiating layer in the continuous phase. The larger particles penetrate further into the combustor main chamber, but are not significantly influenced away from their initial trajectory before ignition occurs. The results show the significant differences in the reaction regimes and combustion behavior when the interaction of different particle sizes in the polydispersed cases expands the reaction zones and affects burning time.

The advantage of these contours is the explicit nature in which they convey the zone of particle ignition and burn out. While experimentally ignition can be fundamentally identified as the location where a sudden increase in luminosity occurs, the determination of particle burn out tends to be much more subjective when post combustion emission is a factor. Olsen and Beckstead [18] note that many investigators do not address this problem, which requires several evaluation methods to accurately and objectively compare experimental burn times.Error! Reference source not found. and Error! Reference source not found. show a comparison of computational polydispersed burn time results with raw experimental data and normalized experimental data with a second order regression. A complete set of solution contours for each monodisperse case investigated is included in Marino [19]. 


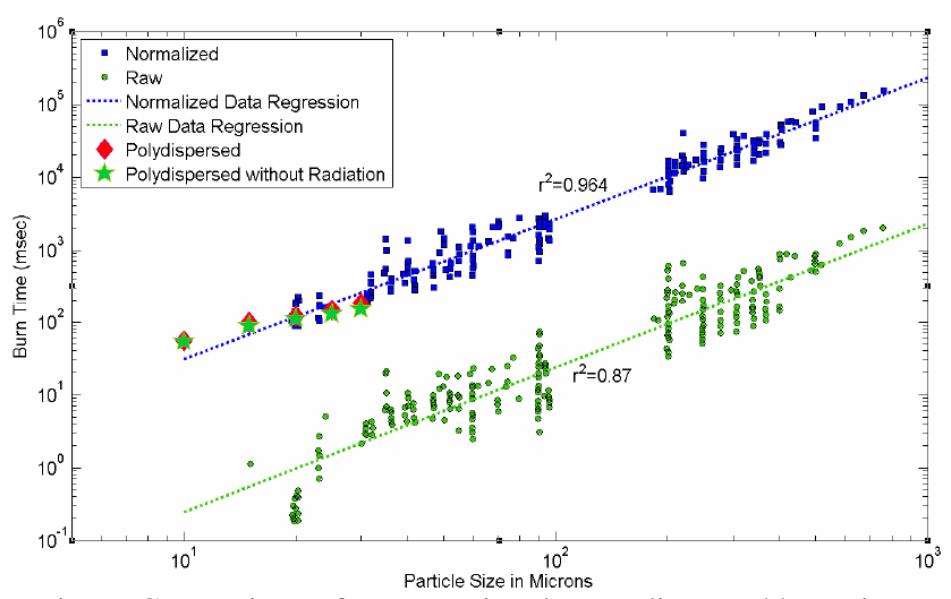

Fig. 7: Comparison of computational monodispersed burn time results with raw experimental data and normalized experimental data with second order regression.

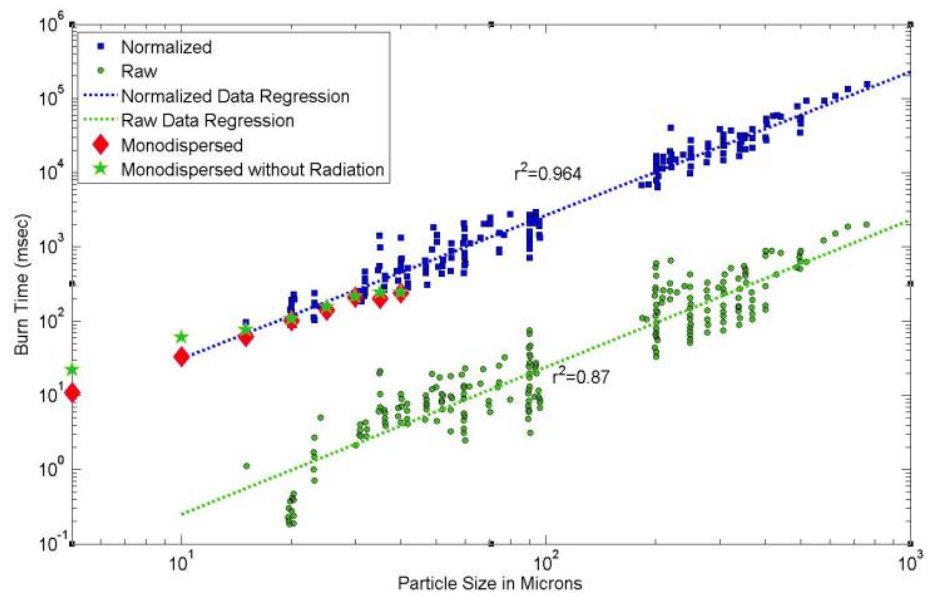

Fig. 8: Comparison of computational polydispersed burn time results with raw experimental data and normalized experimental data with second order regression.

\section{Conclusions}

Beckstead [7] notes discouragingly the relatively large scatter in data due to the diversity of methods used to obtain the data, the variances in data reduction, and the difficulties in experimentally defining accurate burn out. The uncertainty and variability of ignition and burn times can be quantified with the computational method presented herein and an increased understanding of the flow field influence can be obtained. Figure 7 shows a comparison of burn times computed in this study for monodispersed cases, with and without radiation. Figure 8 shows a comparison of burn times computed in this study for polydispersed cases, with and without radiation.

Smaller particles will experience a delay in burn time in the presence of larger particle sizes. Larger particles from about 15 microns up to about 40 microns show a decreased burn time when smaller particles are present. A significant reason for this is due to the increased irradiance from the smaller particles and all the particles within the distribution heat up at nearly the same rate, which suggests a cooperative heat-transfer effect that reduces the range combustion times for polydispersed distributions. The larger distributions also benefit from their increased momentum, typically maintaining a trajectory through the combustion zone.

Smaller particles will experience a delay in ignition time in the presence of larger particle sizes. Larger particles up to about 40 microns may experience a decreased ignition time in the presence of smaller particle sizes. Within the range tested (i.e. mean polydispersed distributions of 10-30 microns), the particles heat up at nearly the same rate, maintaining the same temperature as other particles sizes with respect to axial position. This cooperative heat-transfer effect reduces the range of ignition times for polydispersed distributions when compared to the monodispersed cases. While the polydispersed case with a mean diameter of 10-microns experienced the shorter ignition time, the results also show that ignition times for the higher mean diameter distributions tend to have shorter mean ignition times relative to the monodispersed case.

Radiation causes an increased variability in ignition times due to the radiative emission cooling the particles as well as the continuous phase radiance, which represents valuable energy lost to the combustor exit. There is a clear link between particle size and ignition time, with a much more significant influence on particles in the 5 and 10 micron range, as well as a diminishing effect radiation has on larger particles.

Radiation effects delay the burn time for each particle size in a monodispersed case, but the burn time in polydispersed cases is not as significantly influenced. In a polydispersed case the burn times between radiation cases and non-radiation cases appear to be statistically insignificant with smaller mean particle burn times, with radiative cooling effect delaying burn time for the larger mean particle sizes. This effect is not surprising in view of the observation showing the close rate at which the temperature rises for all particles within a distribution. 


\section{References}

[1] A. R. Keene Jr, "Land and Attack from Under the Sea," The Johns Hopkins University Applied Physics Laboratory, MD, 2001

[2] T. G. Hughes, R. B. Smith, and D. H. Kiely, "Stored Chemical Energy Propulsion System for Underwater Applications," J. Energy, vol. 7, pp. 128-133, 1983.

[3] E. G. Groff and G. M. Faeth, "Steady Metal Combustor as Closed Thermal Energy Source," J. Hydrodynamics, vol. 12, pp. 63-70, 1978.

[4] J. S. Miller and G. I. Pangilinan, "Measurement of Aluminium Combustion in Energetic Formulations," in Proceedings of AIP Conference, vol. 707, no. 1, pp. 867-871, 2004.

[5] J. P. Foote, R. Burton, and H. Krier, "Ignition and Combustion of Aluminium Particles in H2/O2/N2 Combustion Products," Journal of Propulsion and Power, vol. 14, no. 6, pp. 1001-1108, 1998.

[6] T. F. Miller, "Comparisons of Simulation and Experiment in a Linear Al/Steam Combustor," in Proceedings of the 36th JANNAF Combustion Subcommittee Meeting, Cocoa Beach, FL, 1999.

[7] M. W. Beckstead, K. Puduppakkam, P. Thakre, and V. Yang, "Modeling of Combustion and Ignition of SolidPropellant Ingredients," Progress in Energy and Combustion Science, vol. 33, pp. 497-551, 2007.

[8] C. C. Swett, "Effect of Gas Stream Parameters on the Energy and Power Dissipated in a Spark and on Ignition," Third Symposium on Combustion Flame and Explosion Phenomenon, Williams and Wilkins, Baltimore, 1949, pp. 353-361.

[9] D. R. Ballal and A. H. Lefebvre, "Spark Ignition of Turbulent Lowing Gases," In Proceedings of the AIAA Fifteenth Aerospace Sciences Meeting, Los Angeles, 1977, pp. 77-185.

[10] M. W. Beckstead, "Dynamics of Aluminium Combustion.” Journal of Propulsion and Power, July-August 1995.

[11] D. E. Rosner, "Effects of Product Condensation on the Reaction-Enhanced Vaporization Rates on the Transition from Homogeneous to Heterogeneous Reaction in High-Temperature Metal Oxidation," Oxidation of Metals, vol. 4, no. 1, 1972.

[12] M. A. Gurevich, G. E. Ozerova, and A. M. Stepanov, "Heterogeneous Ignition of an Aluminium Particle in Oxygen and Water Vapor," Combustion, Explosion, and Shock Waves, vol. 6, pp. 291-297, 1970.

[13] A. Macek, "Fundamentals of Combustion of Single Aluminium and Beryllium Particles," Eleventh Symposium (International) on Combustion, pp. 203-217, 1967.

[14] M. A. Gurevich, G. E. Ozerova, and A. A. Yurinov, "Effect of an Oxide Film on the Inflamation Characteristics of Aluminium." Combustion, Explosion, and Shock Waves, vol. 14, pp. 448-451, 1978.

[15] J. P. Foote, J. T. Lineberry, B. R. Thompson, and B. C. Winkleman, "Investigation of Aluminium Particle Combustion for Underwater Propulsion Applications." in Proceedings of the Eleventh ONR Propulsion Meeting, West Palm Beach, FL, pp. 09-115, 1998.

[16] M. F. Modest, Radiative Heat Transfer, Academic Press, $2^{\text {nd }}$ Ed., 2003.

[17] N. H. Furnman, Standard Methods of Chemical Analysis, 6th Ed., R.E. Krieger Publishing Co., 1962, pp. 53-55.

[18] S. Olsen and M. Beckstead, "Burn Time Measurements of Single Aluminum Particles in Steam and Carbon Dioxide Mixtures," in Proceedings of $31^{\text {st }}$ Joint Propulsion Conference and Exhibit, AIAA, AIAA-95-2715, San Diego CA, 1995.

[19] T. Marino, "Numerical Analysis to Study the Effects of Solid Fuel Particle Characteristics on Ignition, Burning, and Radiative Emission," Doctoral dissertation, The George Washington University, May 2008. 